OPEN ACCESS

Edited by:

Caoxing Huang,

Nanjing Forestry University, China

Reviewed by:

Liqiu Hu,

Åbo Akademi University, Finland

Jingsan $\mathrm{Xu}$,

Queensland University of Technology, Australia

*Correspondence: Ming-Guo Ma

mg_ma@bjfu.edu.cn

Xing-Xiang Ji

jxx@qlu.edu.cn

Sun-Eun Cho

oregonin@kangwon.ac.kr

Chuanling Si

sichli@tust.edu.cn

Specialty section:

This article was submitted to Green and Sustainable Chemistry,

a section of the journal

Frontiers in Chemistry

Received: 22 September 2021

Accepted: 07 October 2021

Published: 18 November 2021

Citation:

Yuan Q, Liu S, Ma M-G, Ji X-X, Choi S-E and Si C (2021) The Kinetics

Studies on Hydrolysis

of Hemicellulose.

Front. Chem. 9:781291.

doi: 10.3389/fchem.2021.781291

\section{The Kinetics Studies on Hydrolysis of Hemicellulose}

\author{
Qi Yuan ${ }^{1}$, Shan $\mathrm{Liu}^{2}$, Ming-Guo $\mathrm{Ma}^{1 *}$, Xing-Xiang $\mathrm{Ji}^{2 *}$, Sun-Eun $\mathrm{Choi}^{3 *}$ and Chuanling $\mathrm{Si}^{4 *}$ \\ ${ }^{1}$ Engineering Research Center of Forestry Biomass Materials and Bioenergy, Research Center of Biomass Clean Utilization, \\ Beijing Key Laboratory of Lignocellulosic Chemistry, College of Materials Science and Technology, Beijing Forestry University, \\ Beijing, China, ${ }^{2}$ State Key Laboratory of Biobased Material and Green Papermaking, Qilu University of Technology (Shandong \\ Academy of Sciences), Jinan, China, ${ }^{3}$ Department of Forest Biomaterials Engineering, College of Forest and Environmental \\ Sciences, Gangwon National University, Chuncheon, South Korea, ${ }^{4}$ Tianjin Key Laboratory of Pulp and Paper, Tianjin University of \\ Science and Technology, Tianjin, China
}

The kinetics studies is of great importance for the understanding of the mechanism of hemicellulose pyrolysis and expanding the applications of hemicellulose. In the past years, rapid progress has been paid on the kinetics studies of hemicellulose hydrolysis. In this article, we first introduced the hydrolysis of hemicelluloses via various strategies such as autohydrolysis, dilute acid hydrolysis, catalytic hydrolysis, and enzymatic hydrolysis. Then, the history of kinetic models during hemicellulose hydrolysis was summarized. Special attention was paid to the oligosaccharides as intermediates or substrates, acid as catalyst, and thermogravimetric as analyzer method during the hemicellulose hydrolysis. Furthermore, the problems and suggestions of kinetic models during hemicellulose hydrolysis was provided. It expected that this article will favor the understanding of the mechanism of hemicellulose pyrolysis.

Keywords: hemicellulose, hydrolysis, kinetics, oligosaccharides, acid, thermogravimetric analyzer

\section{INTRODUCTION}

Chemical kinetics explore the reaction rate and reaction mechanism of chemical processes, which is often the decisive factor in the process of chemical production (Bazant, 2013; An et al., 2019; Hu et al., 2019; Li et al., 2019; Kumar et al., 2020). In comparison with chemical thermodynamics, chemical kinetics observe the chemical reaction from a dynamic point of view and studies the required time and micro processes for the transformation of the reaction system (Real et al., 2009; Xu R. et al., 2021), whose object is a non-equilibrium dynamic system. Chemical kinetics were used to explore the mechanism of chemical reaction based on the factors, such as temperature, pressure, catalyst, and solvent (Harvey, 2007; Lu et al., 2019; Ma et al., 2020; Xu R. et al., 2020). One can control the reaction conditions, improve the rate of reaction, reduce byproducts, and improve product quality through the chemical kinetics.

Classical chemical kinetics is based on the original experimental data of concentration and time, and obtains some reaction kinetic parameters including reaction rate constant, activation energy, and pre-exponential factor. The research on the kinetics was widely carried out based on elementary reaction kinetics and active intermediates (Zarea, 2002; Liu S. et al., 2021; Liu et al., 2021; Ma et al., 2021). The reaction intermediates were detected and analyzed to understand the reaction mechanism. The chemical kinetics were widely used in chemical engineering, catalysis, pharmacy, and environment (Yang and Lee, 2005; Zazo et al., 2005; Gillespie, 2007). There are many reports on the application of kinetics in biomass pyrolysis (Ranzi et al., 2008; White et al., 2011; Mishra and Mohanty, 2018). Lignocellulosic biomass is one of the most abundant resources, which is 
TABLE 1 | The comparison of four hydrolysis methods.

\section{Hydrolysis methods}

Autohydrolysis

Dilute acid hydrolysis

Catalytic hydrolysis

Enzymatic hydrolysis
Advantage

Low-cost simple production

wide source of materials low cost

Short reaction time; high yield

High specificity mild reaction conditions
Disadvantage

Low yield

High reaction temperature, more byproducts

Corrosive, environmental, and handling problems

Long reaction time; high requirements for equipment a promising source of renewable energy (Du et al., 2019; Liu et al., 2020a; Wang H. et al., 2020; Liu et al., 2021b; Liu et al., 2021c). Lignocellulosic biomass is mainly composed of cellulose, hemicelluloses, and lignin (Liu et al., 2020b; Liu et al., 2020; Liu et al., 2021a; Du et al., 2021b; Liu et al., 2021d; Wang et al., 2021). Hemicellulose is a polysaccharide composed of different types of monosaccharides such as xylose, arabinose, galactose, and so on. The content and composition of hemicellulose vary greatly with plant species, maturity, early and late wood, cell type, and morphological position (Scheller and Ulvskov, 2010). Hemicellulose pyrolysis is a fundamental thermochemical conversion process, which is a very complex reaction (Yang et al., 2007; Du et al., 2021a; Xu T. et al., 2021). Therefore, the exact mechanism for hemicellulose pyrolysis still needs to be explored. Moreover, cellulose is the major source of fermentable sugars for the production of ethanol in biomass, which is protected by a network of lignin and hemicellulose (Girio et al., 2010; Collard and Blin, 2014; Dai et al., 2019; Yang et al., 2019; Chen et al., 2020a; Xu J. et al., 2020). The hemicellulose pyrolysis removes the protecting shield, making the cellulose more susceptible to enzymatic digestion (Chen et al., 2020b; Dai et al., 2020; Huang et al., 2020; Lin et al., 2020; Zhang et al., 2021; Zheng et al., 2021). Therefore, understanding the mechanism of hemicellulose pyrolysis by chemical kinetics is of great importance for the applications of hemicellulose.

The review paper introduced the hydrolysis of hemicelluloses, reviewed the history of kinetic models during hemicellulose hydrolysis, provided the kinetic models, and comparatively evaluated kinetic parameters. The kinetic models were influenced by many parameters such as intermediates, temperature, and catalyst. The oligosaccharides as intermediates or substrates, acid as catalyst, and thermogravimetric as analyzer method were summarized during the hemicellulose hydrolysis. We expect that this review paper would put forward the developments and applications of the hemicelluloses.

\section{HYDROLYSIS OF HEMICELLULOSES}

The structure and composition of hemicellulose vary greatly with biomass species, cell type, morphological position, and pyrolysis methods. The pyrolysis, such as autohydrolysis, dilute acid hydrolysis, catalytic hydrolysis, and enzymatic hydrolysis, is an important strategy to obtain hemicellulose and its derivatives for the fabrication of materials and chemicals (Delbecq et al., 2018). Table 1 displays the comparison of four hydrolysis methods. In the previous review article (Kapu and Trajano, 2014), Kapu and Trajano summarized the hydrolysis mechanism of polysaccharide in softwoods and bamboo in depth, and overviewed the effects of all temperature, time, acid concentration, size, reactor configuration on the hydrolysis comprehensively, and presented the types, strengths, and weaknesses of kinetic models of the hemicellulose hydrolysis. In Negahdar's work, they reported on aqueous-phase hydrolysis of cellulose and hemicelluloses over molecular acidic catalysts in detail (Negahdar et al., 2016). Three approaches, including the simplest kinetic models, oligosaccharides as intermediates, and oligosaccharides as model compounds, were discussed to understand the reaction mechanism systematically.

The autohydrolysis and dilute acid hydrolysis methods are traditional treatments to extract hemicellulose. For example, aspen wood chip was subjected to autohydrolysis with sulfuric acid to extract hemicelluloses (Al-Dajani et al., 2009). It obtained suitable conditions for the extraction of hemicellulose using $\mathrm{H}_{2} \mathrm{SO}_{4}$ at a liquor to wood ratio of $4: 1$ for $4.5 \mathrm{~h}$. In 2016, authors investigated the change in proton concentration for bamboo hemicellulose between autohydrolysis and dilute acid hydrolysis (Kapu et al., 2016). It found that all the acetyl group, ash content, initial acid concentration, and temperature affected the evolution of proton concentration during hydrolysis. The dilute sulfuric acid was used to treat three sugarcane hybrids to explore the removal of hemicellulose on the enzymatic conversion efficiency of glucan (Santos et al., 2018). It obtained the enzymatic glucan conversion of $92 \%-100 \%$ for post-delignification of acid-pretreated samples. A solution of hemicellulosic saccharides was obtained by non-isothermal autohydrolysis from Birch (Rivas et al., 2016). The xylan derived soluble saccharides and furfural with a yield of $80.5 \%$ based on the kinetic modeling. It converted $44.8 \%$ of substrates in furfural at $170^{\circ} \mathrm{C}$ with $1 \%$ sulfuric acid. Recently, Xu Y. et al. investigated the behavior of Populus tomentosa hemicellulose and the formation of furfural in the autohydrolysis process at $160-180^{\circ} \mathrm{C}$ (Xu Y. et al., 2020). The hemicellulose was converted to corresponding monosaccharides at an ultra-high hydrolysis rate. At $180^{\circ} \mathrm{C}$ for $2 \mathrm{~h}$, it achieved the hydrolysis rate of 91, 100, 95, 58, and 37\%, for xylose, rhamnose, galactose, mannose, and glucose from hemicellulose, respectively.

In addition, both acid hydrolysis and enzymatic hydrolysis were successfully developed to obtain xylooligosaccharides based on the dissolving pulp hemicellulose (Wang et al., 2018; Lin et al., 2019; Gu et al., 2020; Lin et al., 2021). It obtained the highest xylooligosaccharides yield of $45.18 \%$ from $1 \%$ sulfuric acid at $120^{\circ} \mathrm{C}$ for $60 \mathrm{~min}$. Meanwhile, it achieved the highest xylooligosaccharides yield of $42.96 \%$ for enzymatic hydrolysis. Lopes et al. also demonstrated the separation of hemicellulosederived sugar of xylose in acidic green ionic liquid (da Costa Lopes and Łukasik, 2018). It achieved very high recovery yields of 
$90.8 \mathrm{wt} \%$ for the ionic liquid and $98.1 \mathrm{wt} \%$ for xylose by alumina treatment. Obviously, the acidic green ionic liquid displayed a similar mechanism of hydrolysis of hemicellulose, compared with acid hydrolysis. Relvas, Morais, and Bogel-Lukasik focused on hydrolysis kinetic models of hemicellulose from wheat straw using novel high-pressure $\mathrm{CO}_{2}-\mathrm{H}_{2} \mathrm{O}$ method (Relvas et al., 2015a). The three accurate kinetic models of xylan conversion, arabinoxylan hydrolysis, and acetyl group hydrolysis were developed to describe the effect of $\mathrm{CO}_{2}$ pressure and reaction time on the intermediate compounds of xylose and arabinose. $\mathrm{CO}_{2}$ had an effect on the hydrolysis kinetics of hemicellulose as the fastest step of polysaccharide hydrolysis in sugars. The initial kinetic constant of the aforementioned reaction was increased by almost $40 \%$ with $\mathrm{CO}_{2}$, compared with the water process. Moreover, the high-pressure $\mathrm{CO}_{2}-\mathrm{H}_{2} \mathrm{O}$ method was also applied to selectively hydrolyze hemicellulose of wheat straw in acetic acid with a low concentration (Li M. et al., 2020). The hemicellulose selective hydrolysis was catalyzed by both carbonic acid and acetic acid. It reached the hemicellulose removal ratio of $82.3 \%$ using high-pressure acetic acid at $180^{\circ} \mathrm{C}$ for $1 \mathrm{~h}$.

Recently, there are various reports on the enzymatic hydrolysis of hemicellulose. Ostadjoo et al., 2019 introduced the efficient enzymatic hydrolysis of hemicellulose using xylanase from Thermomyces lanuginosus (Ostadjoo et al., 2019). The enzymatic process enabled hydrolysis of hemicellulose to soluble oligoxylosaccharides in $>70 \%$ yields. $\mathrm{CO}_{2}$-assisted hydrothermal method was developed for selective degradation of wheat straw hemicellulose to enhance the enzymatic hydrolysis efficiency for glucose (Wang R. et al., 2020). It obtained the significantly high efficiency of enzymatic hydrolysis due to the loose structure after hemicellulose removal. It achieved more than $72.7 \%$ of glucose after enzymatic hydrolysis, compared with merely $30.2 \%$ of untreated sample. More recently, the rational protein engineering strategy was developed to increase the catalytic efficiency for hemicellulose hydrolysis (Jaafar et al., 2021). It observed the improved enzyme catalytic reaction for insoluble substrate and the highest hydrolysis of hemicellulose by producing up to $62 \%$, reducing sugar using variant E449D/ W453Y. Dutta and Chakraborty reported the kinetics and dynamics of two-phase enzymatic hydrolysis of hemicellulose for biofuel production (Dutta and Chakraborty, 2018). The kinetic constants $(\mathrm{Km}, \mathrm{Vmax}, \mathrm{Kx})$ assume mass transfer disguised values at $0-200 \mathrm{rpm}$. The mixing strategy increased xylose yields by $6.3-8 \%$ and reduced sugar yields by $13-20 \%$.

In essence, acid acted as a catalyst during the acid hydrolysis of hemicellulose. In 2012, Ormsby et al. used solid acid catalysts to selective hemicellulose hydrolysis from both biochar and activated carbon (Ormsby et al., 2012). It observed an $85 \%$ conversion of xylan in $2 \mathrm{~h}$ for biochar and $57 \%$ in $24 \mathrm{~h}$ for activated carbon. The temperature increased hydrolysis reaction rate and conversion. In 2015, the solid acid $\mathrm{SO}_{4}{ }^{2-}$ / $\mathrm{Fe}_{2} \mathrm{O}_{3}$ catalyst was found to selectively hydrolyze hemicellulose from wheat straw (Zhong et al., 2015). The hemicellulose hydrolysis yield of $63.5 \%$ was observed with a ratio of wheat straw to catalyst $(\mathrm{w} / \mathrm{w})$ of $1.95: 1$ at $142^{\circ} \mathrm{C}$ for $4.1 \mathrm{~h}$. Dutta and Chakraborty presented a coupled experimental and theoretical framework for quantifying the two-phase enzymatic hydrolysis kinetics of hemicellulose (Dutta and Chakraborty, 2015). The xylose yield increased product inhibition and decreased reducing sugar yields. Relvas et al. used high-pressure $\mathrm{CO}_{2}$ as catalyst for selective hydrolysis of wheat straw hemicellulose (Relvas et al., 2015b). The $\mathrm{CO}_{2}$ induced the in situ formation of carbonic acid, obtaining a high dissolution of wheat straw hemicellulose. For high pressure $\mathrm{CO}_{2}$, it found a decrease in oligosaccharide content, achieving a maximum monomer sugars of $5.7 \mathrm{gL}^{-1}$. In 2020 , the Keggin-type molybdovanadophosphate heteropolyacids were reported as acid catalysts for the soluble mono and oligosaccharides by hydrolytic conversion of hemicellulose (Shatalov, 2020). Of the total crop xylan, 98.5\% was hydrolytically converted into soluble sugars. Moreover, the solid acid sulfated zirconia was used as catalyst for the synthesis of hemicellulose hydrolysate from corncob (Wan et al., 2021). It carried out the soluble sugar concentration of $30.12 \mathrm{~g} \mathrm{~L}^{-1}$ with a yield of $0.33 \mathrm{~g} \mathrm{~g}^{-1}$ corncob and the maximum xylitol yield of $0.76 \mathrm{~g} \mathrm{~g}^{-1}$ from the hemicellulose hydrolysate fermented by C. Tropicalis.

\section{DEVELOPMENT OF CONVENTIONAL KINETIC MODELS DURING HEMICELLULOSE HYDROLYSIS}

As early as 1945, Saeman did pioneering work in developing the kinetics of hydrolysis of wood chips in dilute acid at $170-190^{\circ} \mathrm{C}$ (Saeman, 1945). The author found that the activation energy was independent of the acid concentration, averaged 42,900 calories. In addition, both the increase in acid concentration and temperature resulted in an increase reaction rate. The improved Saeman model was also applied to study the kinetics of hemicellulosic hydrolysis. From then on, there are many reports on the kinetic research of hemicellulosic hydrolysis using well-known Saeman model. Moreover, more and more scholars paid attention to the kinetic models of hemicellulosic hydrolysis. In 1956, Kobayashi and Sakai explored the hydrolysis rates of pentosan of Buna (Fagus crenata Blume) in sulfuric acid at $74,100,115,130$, and $147^{\circ} \mathrm{C}$ (Kobayashi and Sakai, 1956). It found two stages for the hydrolysis of Buna wood pentosan with the same magnitude values for activation energy. Fagan et al. reported the acid hydrolysis kinetics of cellulose in paper refuse in 1971 (Fagan et al., 1971). In general, the hemicelluloses are more hydrolyzed than cellulose. Therefore, it is necessary for utilizing wood as chemicals and fuels to remove the hemicellulose by the pre-hydrolysis step. González et al. applied a kinetic model about the hydrolysis of hemicellulose from wheat straw in sulfuric acid at 34 and $90^{\circ} \mathrm{C}$ in 1986 (González et al., 1986). It yielded complete solubilization of hemicellulose to xylose and arabinose at $90^{\circ} \mathrm{C}$. A two-consecutive reaction mechanism was developed about the kinetic model of acid-catalyzed hydrolysis. Conner and Lorenz used two pre-hydrolysis methods including the Iotech steam explosion process and the Stake process to explore the kinetic modeling of water and dilute acetic acid (5\%) pre-hydrolysis of southern red oak wood (Conner and Lorenz, 1986). Kinetic parameters modeled the xylan removal and the occurrence of 
xylan oligosaccharides, free xylose, furfural, and degradation products. Thereafter, the famous biphasic model was established including "fast-reacting xylan" and "slow-reacting xylan." The biphasic model fitted well the experimental data, compared with the Saeman model. In 1997, three different feedstocks of corn stover, poplar, and switchgrass were treated using dilute sulfuric acid (Esteghlalian et al., 1997). The authors applied first-order reactions to model monomeric constituents and degradation of the monomers by hydrolysis of hemicellulose. They used the actual acid concentration to determine the kinetic parameters of the biphasic model, predicting the percentage of asremaining xylan and xylose. Moreover, Lu and Mosier applied the kinetic model to analyze the maleic acid-catalyzed hemicellulose hydrolysis in corn stover based on the Saeman model and biphasic model ( $\mathrm{Lu}$ and Mosier, 2008b). It achieved the activation energy of $83.3 \pm 10.3 \mathrm{~kJ} \mathrm{~mol}^{-1}$ for hemicellulose hydrolysis by maleic acid. It suggested low-temperature reaction conditions for monomeric xylose yield in the maleic acid-catalyzed reaction based on the Saeman model. It achieved around $80 \%-90 \%$ xylose yields at $100-150^{\circ} \mathrm{C}$ with $0.2 \mathrm{M}$ maleic acid. Furthermore, Sun et al. chose five inorganic salts, such as $\mathrm{ZnCl}_{2}, \mathrm{FeSO}_{4}, \mathrm{Fe}_{2}\left(\mathrm{SO}_{4}\right)_{3}, \mathrm{FeCl}_{3}$, and $\mathrm{Fe}\left(\mathrm{NO}_{3}\right)_{3}$ as catalysts on hemicellulose hydrolysis in control silage (Sun L. et al., 2011). The Saeman model fitted $\mathrm{Fe}\left(\mathrm{NO}_{3}\right)_{3}$ catalyzed hydrolysis for corn stover silage. It obtained the maximum yields of $81.66 \%$ for xylose and $93.36 \%$ for initial xylan. It carried out the activation energies from 44.35 to $86.14 \mathrm{~kJ} \mathrm{~mol}^{-1}$ for hemicellulose hydrolysis in control and from 3.11 to $34.11 \mathrm{~kJ}$ $\mathrm{moL}^{-1}$ in acid silage. Liu et al. reported kinetic model of dilute sulfuric acid-catalyzed hemicellulose hydrolysis in sweet sorghum bagasse for xylose production (Liu et al., 2012). It achieved the pre-exponential factors for the "easy-to-hydrolyze" fraction, the "hard-to-hydrolyze" fraction of hemicellulose, and xylose degradation of $3.53 \times 10^{6}, 1.80 \times 10^{5}$, and $0.62 \mathrm{~min}^{-1}$, respectively, and the activation energies of $60.7,58.1$, and $14.5 \mathrm{~kJ} \mathrm{moL}^{-1}$, respectively. It yielded the xylose for $60 \%$ of hemicellulose weight under $140^{\circ} \mathrm{C}$ for $50 \mathrm{~min}$. Shi et al. developed the kinetics by dilute-acid pretreatment from corn Stover (Shi et al., 2017). The first-order biphasic model assumed that xylan was composed of two different fragments of fast and slow reacting fractions. The oligomers were used as intermediates in the kinetic model. It observed the low activation energies of xylan hydrolysis. Soleimani et al. explored the kinetics of hemicellulose depolymerization and decomposition in oat hull (Soleimani et al., 2018). The generation of xylose was explained by a single-phase kinetic mechanism with product decomposition (two-step sequential reaction). The single-phase mechanism was used to explain the generation of arabinose, furfural, and acetic acid. A biphasic model was applied to explain the generation of glucose in the hydrolysate due to the fast- and slow-releasing fractions into the liquid phase.

In 2003, Belkacemi and Hamoudi investigated the reaction kinetics and model of enzymatic hydrolysis of hemicellulose from corn stalk (Belkacemi and Hamoudi, 2003). A lumped model based on the Michaelis-Menten approach was used to explain the hydrolysis kinetics of two kinds of corn stalk hemicelluloses, such as xylan and heteropolymers, and three lumped species of polymeric, oligomers, and monomers. Dussan et al. also described a lumped kinetic model to simulate the pyrolysis of hemicellulose (Dussan et al., 2017). Authors proposed five new model compounds of acetylated glucuronoxylan, arabinoxylan, (galacto) glucomannan, xyloglucans, and beta-glucan toward replicating the pyrolytic reactivity of hemicellulose. Lloyd and Wyman used the depolymerization model to predict thermochemical hydrolysis of hemicellulose by dilute acid and water-only hemicellulose hydrolysis (Lloyd and Wyman, 2003). A kinetic model integrated the polymeric nature of hemicellulose to explain the polymer decomposition. In 2004, Nabarlatz, Farriol, and Montane developed a kinetic model for the autohydrolysis of xylan, which described the yields of the different reaction products and explained the chemical composition changes of the xylo-oligomers due to reaction temperature and time (Nabarlatz et al., 2004). There were two xylan fractions of three monomers (xylose, arabinose, and acetic acid) with different compositions and reactivity toward hydrolysis.

Rissanen et al. reported the extraction of hemicelluloses from spruce at 90 and $110^{\circ} \mathrm{C}$ (Rissanen et al., 2016). The low temperature dissolution was used to explore the early stage of extraction as the kinetic. $\mathrm{Li}$ et al. investigated the kinetics of hemicelluloses removal from the cold caustic extraction (Li et al., 2017). The authors indicated the hemicelluloses removal process with pseudo zero order kinetics including the bulk phase, transition phase, and residual phase. The fundamentals of hemicelluloses removal were explored by the enzymatic peeling method. Yedro et al. explored the extraction kinetics of hemicelluloses from Holm oak in subcritical water (Yedro et al., 2017; Li X. et al., 2020). It achieved the maximum yield (approximately $60 \%$ ) at $170^{\circ} \mathrm{C}$ for $20 \mathrm{~min}$. Temperature influenced significantly the hydrolysis rate of the macromolecules. Fernández et al. also applied subcritical water to extract hemicelluloses from stone pine, holm oak, and Norway spruce (Fernández et al., 2018). It observed the high activation energy of $88 \mathrm{~kJ} \mathrm{~mol}^{-1}$ for stone pine, $129 \mathrm{~kJ} \mathrm{moL}^{-1}$ for Norway spruce, and $153 \mathrm{~kJ} \mathrm{moL}^{-1}$ for holm oak. Santos-Rocha et al. presented the semi-mechanistic kinetic models of cellulose and hemicellulose for sugarcane straw (Santos-Rocha et al., 2017). The kinetic parameters were explored based on cellobiose, glucose, formic acid, and hydroxymethylfur fural (from cellulosic fraction), and xylose, arabinose, acetic acid, glucuronic acid, and furfural (from hemicellulosic fraction). Kinetic models for both cellulosic and hemicellulosic fractions degradation fitted the experimental data. Köchermann et al. explored kinetics of an aqueous organosolv hemicellulose and $\mathrm{D}$-xylose conversion into furfural between 160 and $200^{\circ} \mathrm{C}$ using three reaction models (Köchermann et al., 2018). Kinetic models showed slight differences for D-xylose conversion and stronger deviations for furfural formation. The formation of a xylose intermediate showed the best performance. Liu F. et al. carried out the inhibitory effects of acetosyringone on xylanase activity by kinetic experiments (Liu et al., 2020). The acetosyringone obviously inhibited the activity of xylanase in a reversible and noncompetitive binding manner. $\mathrm{He}$ et al. developed the dissolution kinetics about the atmospheric sodium 
TABLE 2 | The development summary of kinetic models during hemicellulose hydrolysis.

\begin{tabular}{lll}
\hline Kinetic models & Proposer & \multicolumn{1}{c}{ Reference } \\
\hline Saeman model & Saeman & Saeman,1945 \\
Bidirectional model & Conner & Conner and Lorenz, (1986) \\
Garrote model & Garrote & Garrote et al. (1999) \\
Improved bidirectional model & Borrega & Borrega et al. (2011) \\
Bidirectional dynamic model & Tizazu & Tizazu and Moholkar, (2018)
\end{tabular}

hydroxide-hydrogen peroxide extraction process of hemicellulose in bagasse pith ( $\mathrm{He}$ et al., 2020). The activation energy of $22.19 \mathrm{~kJ} \mathrm{~mol}^{-1}$ indicated the time-dependent dissolution process of hemicellulose, attributing to a diffusioncontrolled process. Chen et al. adopted a two-step model to predict the isothermal torrefaction kinetics of cellulose, hemicelluloses, and lignin at 200,250 , and $300^{\circ} \mathrm{C}$ (Chen et al., 2021). It found hemicelluloses with severe weight loss at $250^{\circ} \mathrm{C}$ due to the relatively weak structure. It achieved the activation energies of cellulose, hemicelluloses, and lignin in the range of 166-260, 48-55, and $59-70 \mathrm{~kJ} \mathrm{~mol}^{-1}$, respectively. Table 2 demonstrates the development summary of kinetic models during hemicellulose hydrolysis.

\section{Effects of Modeling Hemicellulosic Hydrolysis Kinetics}

During the kinetic models for hemicellulose hydrolysis, oligosaccharides are important as intermediates or substrates. In 2005, Carvalheiro et al. reported hemicellulose solubilization and xylo-oligosaccharide production by isothermal autohydrolysis treatments of brewery's spent grain (Carvalheiro et al., 2005). Xylan and arabinan yielded oligosaccharides, monosaccharides (xylose or arabinose), furfural, and other decomposition products in consecutive reaction steps. It developed an arabinoxylan model merging the two proposed models for xylan and arabinan degradation, and including furfural formation from both pentoses. The asproposed models provided an interpretation of the hydrolytic conversion of xylan and arabinan. In 2006, autohydrolysis of Arundo donax L. was reported at $150-195^{\circ} \mathrm{C}$ for hydrolyzing hemicelluloses to xylo-oligosaccharides with high yields of oligomers and monomers (Caparros et al., 2006). It developed a conventional kinetic model, explaining the evolution over time of the hemicelluloses and hemicellulose degradation products. Yáñez et al. assessed the suitability of autohydrolysis as a first biorefinery stage using processing of Acacia dealbata in aqueous media at $170-240^{\circ} \mathrm{C}$ (Yáñez et al., 2009). Xylan (70\%) was converted into xylo-oligosaccharide at $215^{\circ} \mathrm{C}$. The authors developed first-order pseudohomogeneous kinetics model, describing the Acacia dealbata wood solubilization as well as the autohydrolysis of the polysaccharide fractions such as glucan, xylan, arabinosyl, and acetyl substituents of hemicelluloses. In the work of Gullón, they obtained substituted xylo-oligosaccharides and solids in cellulose by the non-isothermal autohydrolysis of rye straw (Gullón et al., 2010). It found $69.2 \%$ of the initial xylan into xylo-oligosaccharide at $208^{\circ} \mathrm{C}$, containing up to $22.4 \mathrm{~g}$ of
oligosaccharide/L. It saccharified $70.6 \%$ of cellulose and $63.8 \%$ of xylan after $48 \mathrm{~h}$ during enzymatic hydrolysis. Kim, Kreke, and Ladisch reported reaction kinetics of xylo-oligosaccharide hydrolysis by dicarboxylic acids (Kim et al., 2013). The hydrolysis of soluble sugar oligomers followed first-order hydrolysis kinetics. The hydrolysis of xylo-oligosaccharide by dicarboxylic acids was modeled using a monophasic model based on Saeman's pseudohomogeneous irreversible first-order reaction kinetics. Branco et al. maximized the yield of oligosaccharides by the selective hemicelluloses removal in autohydrolysis (Branco et al., 2015). It obtained a maximum of $10.4 \mathrm{~g} \mathrm{~L}^{-1}$ of oligosaccharides for a severity factor of 3.6. Gullón et al. reported hemicellulose solubilization and xylooligosaccharides production by non-isothermal autohydrolysis treatments of vine shoots (Gullón et al., 2017). The as-proposed kinetic model maximized the oligosaccharide content and minimized the generation of monosaccharides and sugar decomposition products.

In 2008, Lu et al. studied the xylose by the hydrolysis of corn stover in diluted sulfuric acid at $100^{\circ} \mathrm{C}$ (Lu et al., 2008a). It found the kinetic parameters of mathematical models, predicting the concentrations of xylose, glucose, and furfural in the hydrolysates. Then Jensen et al. compared the kinetic of dilute sulfuric acid hydrolysis of mixtures of hardwoods, softwood, and switchgrass (Jensen et al., 2008). It obtained an activation energy of $76.19 \mathrm{~kJ}$ $\mathrm{mol}^{-1}$ for balsam, $133.44 \mathrm{~kJ} \mathrm{moL}^{-1}$ for red maple, $141.30 \mathrm{~kJ} \mathrm{~mol}^{-1}$ for switchgrass, $142.58 \mathrm{~kJ} \mathrm{~mol}^{-1}$ for aspen, and $171.20 \mathrm{~kJ} \mathrm{~mol}^{-1}$ for basswood. The acid hydrolysis data confirmed the validity of a pseudo first-order mixture model. After that, $\mathrm{Xu}$ et al. researched the kinetics of acid hydrolysis of water-soluble spruce $O$-acetyl galactoglucomannans (Xu et al., 2008). A first-order kinetic model during the acid hydrolysis was used to calculate the reaction rate constants at various $\mathrm{pH}$ values and temperatures. It found the activation energy of $150 \mathrm{~kJ} \mathrm{~mol}^{-1}$ for acid hydrolysis of spruce galactoglucomannans from the Arrhenius plot. In 2014, Rissanen et al. reported kinetics modeling of spruce hemicellulose for chemicals (Rissanen et al., 2014). A first-order model was used to perform the overall extraction data, which fitted the experimental data. It found the activation energy of about $120 \mathrm{~kJ} \mathrm{~mol}^{-1}$ for both chip sizes with different reaction rates and the pre-exponential factor.

In 2009, Morinelly et al. investigated the kinetics of dilute acid hydrolysis for aspen, balsam, and switchgrass at various temperatures, acid concentrations, and reaction times (Morinelly et al., 2009). The four-step kinetic model with firstorder irreversible rate constants fitted the experimental data. The as-proposed kinetic model described the reaction profiles for xylose monomer by the reaction. Meanwhile, the kinetic model described the oligomer data at early reaction time. Pronyk and Mazza reported the kinetic model of hemicellulose hydrolysis from triticale straw (Pronyk and Mazza, 2010). It observed a dependency about the kinetic rate constants with flow rate. Jin et al. investigated the kinetic of hemicellulose hydrolysis of corn stover in dilute acid (Jin et al., 2011). A first-order reaction model fitted the kinetic data of hemicellulose hydrolysis. It observed over $90 \%$ of the xylose monomer yield and below $5.5 \%$ of furfural yield. It obtained the activation energy of $111.6 \mathrm{~kJ} \mathrm{~mol}^{-1}$ for 
xylose and $95.7 \mathrm{~kJ} \mathrm{~mol}^{-1}$ for xylose. Patwardhan, Brown, and Shanks explored the fast pyrolysis product distribution of hemicelluloses from switchgrass (Patwardhan et al., 2011). It achieved the primary pyrolysis products of the as-purified hemicellulose in decreasing abundance, such as $\mathrm{CO}_{2}$, formic acid, char, DAXP2, xylose, acetol, CO, 2-furaldehyde, and AXP. Shen and Wyman applied the kinetic model to explain the enhanced xylose yields from dilute sulfuric acid using reversible fast-reacting xylan and irreversible slow-reacting xylan (Shen and Wyman, 2011). The xylan removal data were simulated by a kinetic model for dilute acid and hydrothermal pretreatment of corn stover. The oligomeric xylose decomposition controlled hydrothermal autocatalytic reactions from xylan to furfural. However, monomeric xylose decomposition controlled dilute acid-catalytic reactions.

As mentioned above, acid was applied as a catalyst during the hemicellulose hydrolysis in acid system. Grénman et al. investigated the kinetics of aqueous extraction of hemicelluloses from spruce in an intensified reactor system (Grénman et al., 2011). A kinetic model fitted the experimental data. It obtained the activation energy of $135 \mathrm{~kJ}$ $\mathrm{mol}^{-1}$. In 2012, Rafiqul and Sakinah also studied the kinetic on acid hydrolysis of Meranti wood sawdust for xylose (Rafiqul and Sakinah, 2012). The kinetic parameters were used to predict the concentration of xylose, glucose, furfural, and acetic acid in the hemicellulosic hydrolysate. It obtained the $6 \%$ sulfuric acid and residence time of $20 \mathrm{~min}$. Enslow and Bell reported the kinetics of Brønsted acid-catalyzed hydrolysis of hemicellulose in green 1ethyl-3-methylimidazolium chloride (Enslow and Bell, 2012). The hemicellulose was hydrolyzed to xylose in $90 \%$ yield. In 2013, Rivas et al. researched the kinetics and manufacturing of levulinic acid from pine wood hemicelluloses via autohydrolysis in sulfuric acid (Rivas et al., 2013). They applied a model involved to interpret the concentration profiles including the major conversion steps such as oligomers into monosaccharides, hexoses into hydroxymethyl furfural, decomposition of this latter into levulinic and formic acids, dehydration of pentoses into furfural, and conversion of this latter into formic acid. It yielded $66 \%$ of the stoichiometric value in levulinic acid under the best conditions. In 2014, kinetic models were developed for the hydrolysis of O-acetyl-galactoglucomannan in homogeneous and heterogeneous catalysts (Salmi et al., 2014). It observed a regular kinetic behavior during the hydrolysis process using homogeneous catalysts $\left(\mathrm{HCl}, \mathrm{H}_{2} \mathrm{SO}_{4}\right.$, oxalic acid, and trifluoroacetic acid) and a prominent autocatalytic effect using heterogeneous cation-exchange catalysts (Amberlyst 15 and Smopex 101). The kinetic models for heterogeneous catalysts were based on the reactivity of the non-hydrolyzed sugar units and the rate constant. The kinetic model described the overall kinetics and product distribution in the hydrolysis of water soluble O-acetyl-galactoglucomannan by homogeneous and heterogeneous catalysts. A hydrogen ion catalytic kinetic model was used to predict the time-dependent behavior of xylo-oligomer, xylose, arabinose, and furfural in hydrolysates in hot water pre-extraction of moso bamboo (Hu et al., 2014). The hydrogen ion catalytic kinetic model introduced the time dependence of the hydrogen ion concentration. The authors calculated the activation energy of $98.2 \mathrm{~kJ} \mathrm{~mol}^{-1}$ for xylan. Moreover, Negahdar et al. investigated the kinetics of the catalytic conversion of cellobioseto sorbitol (Negahdar et al., 2014). In this work, two competing reaction pathways started from cellobiose. It obtained activation energy of $115 \mathrm{~kJ} \mathrm{~mol}^{-1}$ for the hydrolysis of cellobiose and $69 \mathrm{~kJ} \mathrm{~mol}^{-1}$ for subsequent hydrogenation of glucose, and 76 and $103 \mathrm{~kJ} \mathrm{~mol}^{-1}$ with overall high reaction rates at low temperatures for cellobitol formation followed by hydrolysis. Dussan et al. investigated the reaction kinetics of the major components catalyzed by formic acid in the hemicellulose fractions of D-xylose, L-arabinose, and D-glucose (Dussan et al., 2015). The reaction kinetics of solutions were predicted by these models. Chen and Liu used liquid hot water extraction to separate the hemicellulose fraction from dried distiller's grain (Chen and Liu, 2015). A kinetic model was used to introduce the concentration of monomer, oligomer, and sugar units during acid hydrolysis. Santucci et al. evaluated a simplified pseudo-first-order kinetic model for autohydrolysis of hemicelluloses from sugarcane bagasse including all sugars, oligomers, and decomposition products from hemicelluloses (Santucci et al., 2015). Hemicellulose $(61.7 \%$ of $)$ was converted to oligomeric and monomeric sugars. It obtained an activation energy of $143.1 \mathrm{~kJ}$ $\mathrm{mol}^{-1}$ for oligomers, $158.9 \mathrm{~kJ} \mathrm{~mol}^{-1}$ for monomers, and $138.3 \mathrm{~kJ}$ $\mathrm{mol}^{-1}$ for sugar derivatives/decomposition compounds.

The thermogravimetric analyzer (TGA) is a very important method to explore the kinetics of biomass pyrolysis. TGA is a thermal analysis technique used to measure the change in sample mass with temperature through thermobalance and programmed temperature rise method. It can be used to get thermogravimetric curve and weight loss rate curve. By analyzing the curve, the reaction stage can be divided, the corresponding parameters can be calculated, and the pyrolysis law of the sample can be analyzed preliminarily. Rapid progress has been paid on the thermogravimetric kinetic study of hemicellulose hydrolysis. As early as 2011, Chen and Kuo developed the isothermal kinetics to explain the thermal decompositions of hemicellulose, cellulose, lignin, and xylan using TGA (Chen and Kuo, 2011). It achieved the reaction order of hemicellulose, cellulose, lignin, and xylan of 3, 1, 1, and 9, respectively, and the activation energies of 187.06, 124.42, 37.58 , and $67.83 \mathrm{~kJ} \mathrm{~mol}^{-1}$, respectively. This model provided a good evaluation on the thermal degradations of the constituents, expect for cellulose at $300^{\circ} \mathrm{C}$ and hemicellulose at $275^{\circ} \mathrm{C}$. Then Zhou et al. applied TGA and macro-TGA to research kinetics of pyrolysis of hemicellulose, cellulose, and lignin (Zhou et al., 2015). It found the different slow pyrolysis in the TGA and macro-TGA due to the heat transfer process, and the considerable differences of the pyrolysis and fast pyrolysis in macro-TGA. Wang et al. used TGA to explore kinetic of biomass pyrolysis using combined kinetics (Wang et al., 2016). One-step pyrolysis was developed with kinetic parameters of apparent activation energy $221.7 \mathrm{~kJ} \mathrm{~mol}^{-1}$ and pre-exponential factor $4.17 \mathrm{E}+16 \mathrm{~s}^{-1}$. Combined kinetics three-parallel-reaction model fitted the pyrolysis experimental data. It obtained the activation energy order of three pseudo components: $\mathrm{E}_{\text {lignin }}\left(197.3 \mathrm{~kJ} \mathrm{~mol}^{-1}\right)$ $>\mathrm{E}_{\text {cellulose }}\left(176.3 \mathrm{~kJ} \mathrm{~mol}^{-1}\right)>\mathrm{E}_{\text {hemicellulose }}\left(151.1 \mathrm{~kJ} \mathrm{~mol}^{-1}\right)$. The 
TABLE 3 | The activation energy $\left(E / \mathrm{kJ} \mathrm{mol}^{-1}\right)$ in comparison with hemicellulose hydrolysis.

\begin{tabular}{ll}
\hline $\mathbf{E}\left(\mathbf{k J} \mathbf{~ m o l}^{-\mathbf{1}}\right)$ & \multicolumn{1}{c}{ Reference } \\
\hline $83.3 \pm 10.3$ & Lu and Mosier, (2008b) \\
127 & Sun et al. (2011b) \\
187.06 & Chen and Kuo, (2011) \\
135 & Grénman et al. (2011) \\
58.1 & Liu et al. (2012) \\
179.84 & Zhang et al. (2014) \\
151.1 & Wang et al. (2016) \\
162.8 & Chen et al. (2017) \\
95.39 & Yeo et al. (2019) \\
147.2 & Qi et al. (2020) \\
126.31 & Zhu and Zhong, (2020) \\
22.19 & He et al. (2020) \\
$48-55$ & Chen et al. (2021) \\
&
\end{tabular}

pyrolysis of cellulose, hemicellulose, and lignin was comparatively studied using combined kinetics (Yeo et al., 2019). The activation energies for cellulose, hemicellulose, and lignin are 199.66, 95.39, and $174.40 \mathrm{~kJ} \mathrm{~mol}^{-1}$, respectively. Moreover, their group also applied TGA to investigate kinetics of biomass slow pyrolysis using distributed activation energy model, Fraser-Suzuki deconvolution, and iso-conversional method ( $\mathrm{Hu}$ et al., 2015). The TGA technique was used to explore pyrolysis kinetics of pine wood, rice husk, and bamboo (Bambusa chungii). It obtained the activation energy distribution for pseudo components: $\mathrm{E}_{0}$ (lignin) $>\mathrm{E}_{0}$ (cellulose) $>\mathrm{E}_{0} \quad$ (hemicelluloses), $\mathrm{r} \quad$ (lignin) $>\mathrm{r} \quad$ (hemicelluloses) $>\mathrm{r}$ (cellulose). It achieved the apparent activation energy of $162.84 \pm 26.45 \mathrm{~kJ} \mathrm{~mol}^{-1}$ for pine wood, $168.63 \pm 28.47 \mathrm{~kJ} \mathrm{~mol}^{-1}$ for rice husk, and $154.55 \pm 26.49 \mathrm{~kJ} \mathrm{~mol}^{-1}$ for bamboo, respectively. A TGA was developed to explore the pyrolysis kinetic analysis of the three pseudocomponents of cellulose, hemicellulose, and lignin (Chen et al., 2017). The activation energies of cellulose, hemicellulose, and lignin pyrolysis of $112.6,162.8$, and $156.8 \mathrm{~kJ}$ were obtained using the modulated temperature method. The pyrolytic mechanism of cellulose, hemicellulose, and lignin was investigated using TGA (Yeo et al., 2019). The activation energies for cellulose, hemicellulose, and lignin are 199.66, 95.39, and $174.40 \mathrm{~kJ}$ $\mathrm{mol}^{-1}$, respectively. Lei et al. reported thermal pyrolysis kinetics of hemicellulose from Camellia Oleifera Shell by TGA (Lei et al., 2019). Thermal pyrolysis kinetics of Camellia Oleifera Shell hemicelluloses were investigated based on the Coats-Redfern, Flynn-Wall-Ozawa, and Kissinger-Akahira-Sunose models. The thermal pyrolysis mechanism of Camellia Oleifera Shell hemicelluloses was a one-dimensional diffusion reaction analyzed by the Coats-Redfern model. The activation energies of Camellia Oleifera Shell hemicelluloses ranged from 175.07 to $247.87 \mathrm{~kJ}$ $\mathrm{mol}^{-1}$ and from 174.74 to $252.50 \mathrm{~kJ} \mathrm{~mol}^{-1}$ calculated by Flynn-Wall-Ozawa and Kissinger-Akahira-Sunose, respectively. Recently, the TGA method was used to isolate hemicellulose, cellulose, and their mixture (Ding et al., 2020). The activation energy and pre-exponential factor influenced the pyrolysis process of mixture. Diez et al. reported the determination of hemicellulose, cellulose, and lignin content by TGA and pseudocomponent kinetic model (Díez et al., 2020). It obtained the good characteristic kinetic parameters of each fraction. Zhu and Zhong investigated interactions among biomass components on pyrolysis kinetics including pyrolysis experiments of individual components, synthetic biomass, and natural biomass on a TGA (Zhu and Zhong, 2020). It obtained the sharp pyrolysis behavior of cellulose with low pyrolysis reaction order (1.38), high activation energy $\left(168.61 \mathrm{~kJ} \mathrm{~mol}^{-1}\right)$, and high pre-exponential factor $(3.50 \mathrm{E}+12 / \mathrm{s})$. The pyrolysis behavior of hemicellulose and lignin had a high pyrolysis reaction order $(2.30,1.51)$, low activation energy (126.31, $\left.87.21 \mathrm{~kJ} \mathrm{~mol}^{-1}\right)$, and low pre-exponential factor $(9.67 \mathrm{E}+09$, $2.59 \mathrm{E}+05 / \mathrm{s})$. Table 3 presents the comparison for activation energy of hemicellulose hydrolysis.

Besides the kinetic models during hemicellulose hydrolysis, there are reports on the kinetics of dye and hydrogels. In Batzias's work, they explored the simulation of batch and column kinetics of methylene blue and red basic 22 adsorption on mild acid hydrolyzed wheat straw as an adsorbent for wastewater dye removal (Batzias et al., 2009). Moreover, the pH-responsive hemicellulose hydrogels were prepared as carrier for controlled drug delivery (Sun et al., 2013). The swelling kinetics of the hydrogels followed Fickian diffusion process. Sun et al. synthesized stimuli-responsive porous hydrogels from wheat straw hemicellulose using $\mathrm{CaCO}_{3}$ as porogen for the removal of methylene blue (Sun et al., 2015b). The adsorption data was reported to be fitted to the pseudo-first-order, pseudo-secondorder, and intra-particle diffusion kinetics models. The xylan/ poly (acrylic acid) magnetic nanocomposite hydrogel was prepared from wheat straw xylan and $\mathrm{Fe}_{3} \mathrm{O}_{4}$ nanoparticles for methylene blue removal (Sun et al., 2015a). It achieved the adsorption isotherm of the Langmuir model and the pseudosecond-order kinetic model of the adsorption process. Recently, high-performance superabsorbent hydrogels were fabricated by using waste hemicelluloses lye (Liu et al., 2019). It achieved the adsorption kinetics and isotherms of the composites, and the synergy effect of polyvinyl alcohol and bentonite.

\section{CONCLUSION AND OUTLOOK}

In summary, there is a long history about kinetics modeling of hemicellulose hydrolysis. Recently, it achieved the obvious development of kinetics modeling of hemicellulose hydrolysis. Various parameters, such as process, intermediates, temperature, catalyst, solvent, and systematic errors, received more attention for the kinetic models. In general, the hemicelluloses have different structures, contents, and compositions with plant species, maturity, early and late wood, cell type, and morphological position. Exploring the kinetics modeling is of great importance for understanding the mechanism of hemicellulose hydrolysis.

The kinetics modeling of hemicellulose hydrolysis still needs to be explored due to the complex structure and composition of hemicellulose. It is often carried out for the hemicellulose hydrolysis in a closed system. It is difficult to obtain the 
intrinsic parameters and real mechanism during the hemicellulose hydrolysis. It is also very difficult to study the kinetics of hemicellulose hydrolysis due to its complex reaction process and many influencing factors. The kinetic law based on elementary reaction conforms to the law of mass action. However, the course of most chemical reactions indicated that there existed several steps (elementary reactions) during hemicellulose hydrolysis. Therefore, accurate measurement is very important in kinetics modeling. It is urgent to establish a method for detecting active intermediates from hemicellulose. The kinetics modeling is usually derived from several assumptions. For example, the hydrolysis of xylanase reactions follows the firstorder kinetic reaction equation and the hydrolysis of hemicellulose was not affected by other components in the cell wall. Arrhenius equation is a formula for the variation of chemical reaction rate constant with temperature. It should be noted that the activation energy $E a$, as a constant independent of temperature, fits the experimental result in a certain temperature range. However, the activation energy is related to temperature in the wide temperature range or complex reaction, which is not applicable to some complex reactions. Moreover, the first premise of Arrhenius formula is that the reactions at different temperatures are consistent. However, the hemicellulose hydrolysis has different reactions at different temperatures. In short, the complexity of hemicellulose hydrolysis, closed system, and kinetics modeling itself cannot be overstated. Obviously, the development of chemical kinetics benefits from the development of modern

\section{REFERENCES}

Al-Dajani, W. W., Tschirner, U. W., and Jensen, T. (2009). Pre-extraction of Hemicelluloses and Subsequent Kraft Pulping Part II: Acid- and Autohydrolysis. Tappi J. 8 (9), 30-37.

An, L., Si, C., Wang, G., Sui, W., and Tao, Z. (2019). Enhancing the Solubility and Antioxidant Activity of High-Molecular-Weight Lignin by Moderate Depolymerization via In Situ Ethanol/acid Catalysis. Ind. Crops Prod. 128, 177-185. doi:10.1016/j.indcrop.2018.11.009

Andérez Fernández, M., Rissanen, J., Pérez Nebreda, A., Xu, C., Willför, S., García Serna, J., et al. (2018). Hemicelluloses from Stone pine, Holm Oak, and Norway spruce with Subcritical Water Extraction - Comparative Study with Characterization and Kinetics. J. Supercrit. Fluids 133, 647-657. doi:10.1016/ j.supflu.2017.07.001

Batzias, F., Sidiras, D., Schroeder, E., and Weber, C. (2009). Simulation of Dye Adsorption on Hydrolyzed Wheat Straw in Batch and Fixed-Bed Systems. Chem. Eng. J. 148 (2-3), 459-472. doi:10.1016/j.cej.2008.09.025

Bazant, M. Z. (2013). Theory of Chemical Kinetics and Charge Transfer Based on Nonequilibrium Thermodynamics. Acc. Chem. Res. 46 (5), 1144-1160. doi:10.1021/ar300145c

Belkacemi, K., and Hamoudi, S. (2003). Enzymatic Hydrolysis of Dissolved Corn Stalk Hemicelluloses: Reaction Kinetics and Modeling. J. Chem. Technol. Biotechnol. 78 (7), 802-808. doi:10.1002/jctb.865

Borrega, M., Nieminen, K., and Sixta, H. (2011). Degradation Kinetics of the Main Carbohydrates in Birch wood during Hot Water Extraction in a Batch Reactor at Elevated Temperatures. Bioresour. Technology 102 (22), 10724-10732. doi:10.1016/j.biortech.2011.09.027

Branco, P. C., Dionísio, A. M., Torrado, I., Carvalheiro, F., Castilho, P. C., and Duarte, L. C. (2015). Autohydrolysis of Annona Cherimola Mill. Seeds: Optimization, Modeling and Products Characterization. Biochem. Eng. J. 104, 2-9. doi:10.1016/j.bej.2015.06.006 detection methods, especially surface analysis and rapid tracking methods. It expected that the kinetics modeling of hemicellulose hydrolysis will favor the applications of hemicellulose in the near future.

\section{AUTHOR CONTRIBUTIONS}

QY, SL, and M-GM handled the investigation. X-XJ, S-EC, and CS were in charge of the supervision. QY, SL, and M-GM wrote the original draft. M-GM, X-XJ, S-EC, and CS wrote, reviewed, and edited the manuscript.

\section{FUNDING}

The financial support from the National Key R\&D Program of China (2019YFC1905901) is gratefully acknowledged, and this work was also partially supported by 2021 Universities Leading Lab-Specific Start-Ups through the National Research Foundation of Korea (NRF) grant funded by the Korea government (MSIT), R\&D program for Forest Science Technology (2019151D10-2023-0301) provided by Korea Forest Service (Korea Forestry Promotion Institute), work was also partially supported by the Technology Development Program (S3030198) funded by the Ministry of SMEs and Startups (MSS, Korea) work to S.E.C.

Caparrós, S., Garrote, G., Ariza, J., and López, F. (2006). Autohydrolysis of Arundo donax L., a Kinetic Assessment. Ind. Eng. Chem. Res. 45 (26), 8909-8920. doi:10.1021/ie061166x

Carvalheiro, F., Garrote, G., Parajó, J. C., Pereira, H., and Gírio, F. M. (2005). Kinetic Modeling of Breweryapos;s Spent Grain Autohydrolysis. Biotechnol. Prog. 21, 233-243. doi:10.1021/bp049764z

Chen, H., and Liu, S. (2015). A Kinetic Study of DDGS Hemicellulose Acid Hydrolysis and NMR Characterization of DDGS Hydrolysate. Appl. Biochem. Biotechnol. 177 (1), 162-174. doi:10.1007/s12010-015-1735-7

Chen, S., Wang, G., Sui, W., Parvez, A. M., Dai, L., and Si, C. (2020a). Novel LigninBased Phenolic Nanosphere Supported Palladium Nanoparticles with Highly Efficient Catalytic Performance and Good Reusability. Ind. Crops Prod. 145, 112164. doi:10.1016/j.indcrop.2020.112164

Chen, S., Wang, G., Sui, W., Parvez, A. M., and Si, C. (2020b). Synthesis of LigninFunctionalized Phenolic Nanosphere Supported Ag Nanoparticles with Excellent Dispersion Stability and Catalytic Performance. Green. Chem. 22, 2879-2888. doi:10.1039/c9gc04311j

Chen, T., Li, L., Zhao, R., and Wu, J. (2017). Pyrolysis Kinetic Analysis of the Three Pseudocomponents of Biomass-Cellulose, Hemicellulose and Lignin. J. Therm. Anal. Calorim. 128 (3), 1825-1832. doi:10.1007/s10973-016-6040-3

Chen, W.-H., Fong Eng, C., Lin, Y.-Y., Bach, Q.-V., Ashokkumar, V., and Show, P.L. (2021). Two-step Thermodegradation Kinetics of Cellulose, Hemicelluloses, and Lignin under Isothermal Torrefaction Analyzed by Particle Swarm Optimization. Energ. Convers. Management 238, 114116. doi:10.1016/ j.enconman.2021.114116

Chen, W.-H., and Kuo, P.-C. (2011). Isothermal Torrefaction Kinetics of Hemicellulose, Cellulose, Lignin and Xylan Using Thermogravimetric Analysis. Energy 36 (11), 6451-6460. doi:10.1016/j.energy.2011.09.022

Collard, F.-X., and Blin, J. (2014). A Review on Pyrolysis of Biomass Constituents: Mechanisms and Composition of the Products Obtained from the Conversion of Cellulose, Hemicelluloses and Lignin. Renew. Sustainable Energ. Rev. 38, 594-608. doi:10.1016/j.rser.2014.06.013 
da Costa Lopes, A. M., and Łukasik, R. M. (2018). Separation and Recovery of a Hemicellulose-Derived Sugar Produced from the Hydrolysis of Biomass by an Acidic Ionic Liquid. ChemSusChem 11 (6), 1099-1107. doi:10.1002/ cssc. 201702231

Dai, L., Ma, M., Xu, J., Si, C., Wang, X., Liu, Z., et al. (2020). All-Lignin-Based Hydrogel with Fast pH-Stimuli Responsiveness for Mechanical Switching and Actuation. Chem. Mater. 32, 4324-4330. doi:10.1021/acs.chemmater.0c01198

Dai, L., Zhu, W., Lu, J., Kong, F., Si, C., and Ni, Y. (2019). A Lignin-Containing Cellulose Hydrogel for Lignin Fractionation. Green. Chem. 21, 5222-5230. doi:10.1039/c9gc01975h

Delbecq, F., Wang, Y., MuralidharaEl Ouardi, A. K., El Ouardi, K., Marlair, G., and Len, C. (2018). Hydrolysis of Hemicellulose and Derivatives-A Review of Recent Advances in the Production of Furfural. Front. Chem. 6, 146. doi:10.3389/fchem.2018.00146

Díez, D., Urueña, A., Piñero, R., Barrio, A., and Tamminen, T. (2020). Determination of Hemicellulose, Cellulose, and Lignin Content in Different Types of Biomasses by Thermogravimetric Analysis and Pseudocomponent Kinetic Model (TGA-PKM Method). Processes 8 (9), 1048. doi:10.3390/ pr8091048

Ding, Y., Huang, B., Li, K., Du, W., Lu, K., and Zhang, Y. (2020). Thermal Interaction Analysis of Isolated Hemicellulose and Cellulose by Kinetic Parameters during Biomass Pyrolysis. Energy 195, 117010. doi:10.1016/ j.energy.2020.117010

dos Santos Rocha, M. S. R., Pratto, B., de Sousa, R., Almeida, R. M. R. G., and Cruz, A. J. G. d. (2017). A Kinetic Model for Hydrothermal Pretreatment of Sugarcane Straw. Bioresour. Technology 228, 176-185. doi:10.1016/j.biortech.2016.12.087

Du, H., Liu, W., Zhang, M., Si, C., Zhang, X., and Li, B. (2019). Cellulose Nanocrystals and Cellulose Nanofibrils Based Hydrogels for Biomedical Applications. Carbohydr. Polym. 209, 130-144. doi:10.1016/ j.carbpol.2019.01.020

Du, H., Parit, M., Liu, K., Zhang, M., Jiang, Z., Huang, T.-S., et al. (2021a). Multifunctional Cellulose Nanopaper with superior Water-Resistant, Conductive, and Antibacterial Properties Functionalized with Chitosan and Polypyrrole. ACS Appl. Mater. Inter. 13 (27), 32115-32125. doi:10.1021/ acsami.1c06647

Du, H., Zhang, M., Liu, K., Parit, M., Jiang, Z., Zhang, X., et al. (2022b). Conductive PEDOT:PSS/cellulose Nanofibril Paper Electrodes for Flexible Supercapacitors with superior Areal Capacitance and Cycling Stability. Chem. Eng. J. 428, 131994. doi:10.1016/j.cej.2021.131994

Dussan, K., Dooley, S., and Monaghan, R. (2017). Integrating Compositional Features in Model Compounds for a Kinetic Mechanism of Hemicellulose Pyrolysis. Chem. Eng. J. 328, 943-961. doi:10.1016/j.cej.2017.07.089

Dussan, K., Girisuta, B., Lopes, M., Leahy, J. J., and Hayes, M. H. B. (2015). Conversion of Hemicellulose Sugars Catalyzed by Formic Acid: Kinetics of the Dehydration ofD-Xylose,L-Arabinose, andD-Glucose. ChemSusChem 8 (8), 1411-1428. doi:10.1002/cssc.201403328

Dutta, S. K., and Chakraborty, S. (2015). Kinetic Analysis of Two-phase Enzymatic Hydrolysis of Hemicellulose of Xylan Type. Bioresour. Technology 198, 642-650. doi:10.1016/j.biortech.2015.09.066

Dutta, S. K., and Chakraborty, S. (2018). Mixing Effects on the Kinetics and the Dynamics of Two-phase Enzymatic Hydrolysis of Hemicellulose for Biofuel Production. Bioresour. Technology 259, 276-285. doi:10.1016/ j.biortech.2018.03.042

Enslow, K. R., and Bell, A. T. (2012). The Kinetics of Brønsted Acid-Catalyzed Hydrolysis of Hemicellulose Dissolved in 1-Ethyl-3-Methylimidazolium Chloride. RSC Adv. 2 (26), 10028. doi:10.1039/C2RA21650G

Esteghlalian, A., Hashimoto, A. G., Fenske, J. J., and Penner, M. H. (1997). Modeling and Optimization of the Dilute-Sulfuric-Acid Pretreatment of Corn stover, poplar and Switchgrass. Bioresour. Technology 59, 129-136. doi:10.1016/s0960-8524(97)81606-9

Fagan, R. D., Grethlein, H. E., Converse, A. O., and Porteous, A. (1971). Kinetics of the Acid Hydrolysis of Cellulose Found in Paper Refuse. Environ. Sci. Technol. 5 (6), 545-547. doi:10.1021/es60053a006

Garrote, G., Domínguez, H., and Parajó, J. C. (1999). Hydrothermal Processing of Lignocellulosic Materials. Holz als Roh- und Werkstoff 57 (3), 191-202. doi:10.1007/s001070050039

Gillespie, D. T. (2007). Stochastic Simulation of Chemical Kinetics. Annu. Rev. Phys. Chem. 58, 35-55. doi:10.1146/annurev.physchem.58.032806.104637
Gírio, F. M., Fonseca, C., Carvalheiro, F., Duarte, L. C., Marques, S., and BogelŁukasik, R. (2010). Hemicelluloses for Fuel Ethanol: A Review. Bioresour. Technology 101 (13), 4775-4800. doi:10.1016/j.biortech.2010.01.088

González, G., López-Santín, J., Caminal, G., and Solà, C. (1986). Dilute Acid Hydrolysis of Wheat Straw Hemicellulose at Moderate Temperature: A Simplified Kinetic Model. Biotechnol. Bioeng. 28 (2), 288-293. doi:10.1002/ bit.260280219

González, G., López-Santín, J., Caminal, G., and Solà, C. (1986). Dilute Acid Hydrolysis of Wheat Straw Hemicellulose at Moderate Temperature: A Simplified Kinetic Model. Biotechnol. Bioeng. 28 (2), 288-293. doi:10.1002/ bit. 260280219

Grénman, H., Eränen, K., Krogell, J., Willför, S., Salmi, T., and Murzin, D. Y. (2011). Kinetics of Aqueous Extraction of Hemicelluloses from Spruce in an Intensified Reactor System. Ind. Eng. Chem. Res. 50 (7), 3818-3828. doi:10.1021/ie101946c

Gu, J., Pei, W., Tang, S., Yan, F., Peng, Z., Huang, C., et al. (2020). Procuring Biologically Active Galactomannans from Spent Coffee Ground (SCG) by Autohydrolysis and Enzymatic Hydrolysis. Int. J. Biol. Macromolecules 149, 572-580. doi:10.1016/j.ijbiomac.2020.01.281

Gullón, B., Eibes, G., Dávila, I., Vila, C., Labidi, J., and Gullón, P. (2017). Valorization of Vine Shoots Based on the Autohydrolysis Fractionation Optimized by a Kinetic Approach. Ind. Eng. Chem. Res. 56 (48), 14164-14171. doi:10.1021/acs.iecr.7b02833

Gullón, B., Yáñez, R., Alonso, J. L., and Parajó, J. C. (2010). Production of Oligosaccharides and Sugars from rye Straw: a Kinetic Approach. Bioresour. Technology 101 (17), 6676-6684. doi:10.1016/j.biortech.2010.03.080

Harvey, J. N. (2007). Understanding the Kinetics of Spin-Forbidden Chemical Reactions. Phys. Chem. Chem. Phys. 9 (3), 331-343. doi:10.1039/b614390c

He, L., Chen, D., Yang, S., Peng, L., Zhang, J., Guan, Q., et al. (2020). Deep Insights into the Atmospheric Sodium Hydroxide-Hydrogen Peroxide Extraction Process of Hemicellulose in Bagasse Pith: Technical Uncertainty, Dissolution Kinetics Behavior, and Mechanism. Ind. Eng. Chem. Res. 59 (21), 10150-10159. doi:10.1021/acs.iecr.0c01076

Hu, H.-C., Chai, X.-S., Zhan, H.-Y., Barnes, D., Huang, L.-L., and Chen, L.-H. (2014). Hydrogen Ion Catalytic Kinetic Model of Hot Water Preextraction for Production of Biochemicals Derived from Hemicellulose Using Moso Bamboo (Phyllostachys Pubescens). Ind. Eng. Chem. Res. 53 (29), 11684-11690. doi:10.1021/ie502261m

Hu, L., Du, H., Liu, C., Zhang, Y., Yu, G., Zhang, X., et al. (2019). Comparative Evaluation of the Efficient Conversion of Corn Husk Filament and Corn Husk Powder to Valuable Materials via a Sustainable and Clean Biorefinery Process. ACS Sustainable Chem. Eng. 7, 1327-1336. doi:10.1021/acssuschemeng.8b05017

Hu, M., Chen, Z., Wang, S., Guo, D., Ma, C., Zhou, Y., et al. (2016). Thermogravimetric Kinetics of Lignocellulosic Biomass Slow Pyrolysis Using Distributed Activation Energy Model, Fraser-Suzuki Deconvolution, and IsoConversional Method. Energ. Convers. Management 118, 1-11. doi:10.1016/ j.enconman.2016.03.058

Huang, C., Zheng, Y., Lin, W., Shi, Y., Huang, G., and Yong, Q. (2020). Removal of Fermentation Inhibitors from Pre-hydrolysis Liquor Using Polystyrene Divinylbenzene Resin. Biotechnol. Biofuels 13, 188. doi:10.1186/s13068-02001828-3

Jaafar, N. R., Ayob, S. N., Abd Rahman, N. H., Abu Bakar, F. D., Murad, A. M. A., and Illias, R. M. (2021). Rational Protein Engineering of $a-L-$ arabinofuranosidase from Aspergillus niger for Improved Catalytic Hydrolysis Efficiency on Kenaf Hemicellulose. Process Biochem. 102, 349-359. doi:10.1016/j.procbio.2020.12.012

Jensen, J., Morinelly, J., Aglan, A., Mix, A., and Shonnard, D. R. (2008). Kinetic Characterization of Biomass Dilute Sulfuric Acid Hydrolysis: Mixtures of Hardwoods, Softwood, and Switchgrass. Aiche J. 54 (6), 1637-1645. doi:10.1002/aic.11467

Jin, Q., Zhang, H., Yan, L., Qu, L., and Huang, H. (2011). Kinetic Characterization for Hemicellulose Hydrolysis of Corn stover in a Dilute Acid Cycle spray FlowThrough Reactor at Moderate Conditions. Biomass and Bioenergy 35 (10), 4158-4164. doi:10.1016/j.biombioe.2011.06.050

Kapu, N. S., Yuan, Z., Chang, X. F., Beatson, R., Martinez, D. M., and Trajano, H. L. (2016). Insight into the Evolution of the Proton Concentration during Autohydrolysis and Dilute-Acid Hydrolysis of Hemicellulose. Biotechnol. Biofuels 9, 224. doi:10.1186/s13068-016-0619-6 
Kim, Y., Kreke, T., and Ladisch, M. R. (2013). Reaction Mechanisms and Kinetics of Xylo-Oligosaccharide Hydrolysis by Dicarboxylic Acids. Aiche J. 59 (1), 188-199. doi:10.1002/aic. 13807

Kobayashi, T., and Sakai, Y. (1956). Hydrolysis Rate of Pentosan of Hardwood in Dilute Sulfuric Acid. Bull. Agric. Chem. Soc. Jpn. 20 (1), 1-7. doi:10.1080/ 03758397.1956.10857296

Köchermann, J., Mühlenberg, J., and Klemm, M. (2018). Kinetics of Hydrothermal Furfural Production from Organosolv Hemicellulose and D-Xylose. Ind. Eng. Chem. Res. 57 (43), 14417-14427. doi:10.1021/acs.iecr.8b03402

Kumar, A., Sharma, G., Naushad, M., Al-Muhtaseb, A. a. H., García-Peñas, A., Mola, G. T., et al. (2020). Bio-inspired and Biomaterials-Based Hybrid Photocatalysts for Environmental Detoxification: A Review. Chem. Eng. J. 382, 122937. doi:10.1016/j.cej.2019.122937

Lei, Z., Wang, S., Fu, H., Gao, W., Wang, B., Zeng, J., et al. (2019). Thermal Pyrolysis Characteristics and Kinetics of Hemicellulose Isolated from Camellia Oleifera Shell. Bioresour. Technology 282, 228-235. doi:10.1016/ j.biortech.2019.02.131

Li, J., Hu, H., Li, H., Huang, L., Chen, L., and Ni, Y. (2017). Kinetics and Mechanism of Hemicelluloses Removal from Cellulosic Fibers during the Cold Caustic Extraction Process. Bioresour. Technology 234, 61-66. doi:10.1016/j.biortech.2017.03.026

Li, M., Yang, X., Lu, T., and Zhou, L. (2020a). Selective Hydrolysis of Hemicellulose Component of Wheat Straw in High-pressure CO 2 and Water with Low Concentration of Acetic Acid. J. Chem. Technol. Biotechnol. 95 (8), 2237-2242. doi:10.1002/jctb.6411

Li, X., Lu, X., Nie, S., Liang, M., Yu, Z., Duan, B., et al. (2020b). Efficient Catalytic Production of Biomass-Derived Levulinic Acid over Phosphotungstic Acid in Deep Eutectic Solvent. Ind. Crops Prod. 145, 112154. doi:10.1016/ j.indcrop.2020.112154

Li, X., Xu, R., Yang, J., Nie, S., Liu, D., Liu, Y., et al. (2019). Production of 5hydroxymethylfurfural and Levulinic Acid from Lignocellulosic Biomass and Catalytic Upgradation. Ind. Crops Prod. 130, 184-197. doi:10.1016/ j.indcrop.2018.12.082

Lin, W., Chen, D., Yong, Q., Huang, C., and Huang, S. (2019). Improving Enzymatic Hydrolysis of Acid-Pretreated Bamboo Residues Using Amphiphilic Surfactant Derived from Dehydroabietic Acid. Bioresour. Technology 293, 122055. doi:10.1016/j.biortech.2019.122055

Lin, W., Xing, S., Jin, Y., Lu, X., Huang, C., and Yong, Q. (2020). Insight into Understanding the Performance of Deep Eutectic Solvent Pretreatment on Improving Enzymatic Digestibility of Bamboo Residues. Bioresour. Technology 306, 123163. doi:10.1016/j.biortech.2020.123163

Lin, W., Yang, J., Zheng, Y., Huang, C., and Yong, Q. (2021). Understanding the Effects of Different Residual Lignin Fractions in Acid-Pretreated Bamboo Residues on its Enzymatic Digestibility. Biotechnol. Biofuels 14, 143. doi:10.1186/s13068-021-01994-y

Liu, F., Xu, W.-F., Mu, H., Lv, Z.-R., Peng, J., Guo, C., et al. (2020). Inhibition Kinetics of Acetosyringone on Xylanase in Hydrolysis of Hemicellulose. Biosci. Biotechnol. Biochem. 84 (9), 1788-1798. doi:10.1080/09168451.2020.1767499

Liu, H., Du, H., Zheng, T., Liu, K., Ji, X., Xu, T., et al. (2021a). Cellulose Based Composite Foams and Aerogels for Advanced Energy Storage Devices. Chem. Eng. J. 426, 130817. doi:10.1016/j.cej.2021.130817

Liu, H., Xu, T., Liu, K., Zhang, M., Liu, W., Li, H., et al. (2021b). Lignin-based Electrodes for Energy Storage Application. Ind. Crops Prod. 165, 113425. doi:10.1016/j.indcrop.2021.113425

Liu, K., Du, H., Zheng, T., Liu, H., Zhang, M., Zhang, R., et al. (2021c). Recent Advances in Cellulose and its Derivatives for Oilfield Applications. Carbohydr. Polym. 259, 117740. doi:10.1016/j.carbpol.2021.117740

Liu, K., Du, H., Zheng, T., Liu, W., Zhang, M., Liu, H., et al. (2021d). Lignincontaining Cellulose Nanomaterials: Preparation and Applications. Green. Chem. doi:10.1039/d1gc02841c

Liu, S., Du, H., Liu, K., Ma, M.-G., Kwon, Y.-E., Si, C., et al. (2021e). Flexible and Porous Co3O4-Carbon Nanofibers as Binder-free Electrodes for Supercapacitors. Adv. Compos. Hybrid. Mater. 4. doi:10.1007/s42114-02100344-8

Liu, W., Du, H., Liu, H., Xie, H., Xu, T., Zhao, X., et al. (2020a). Highly Efficient and Sustainable Preparation of Carboxylic and Thermostable Cellulose Nanocrystals via $\mathrm{FeCl} 3$-Catalyzed Innocuous Citric Acid Hydrolysis. ACS Sustainable Chem. Eng. 8, 16691-16700. doi:10.1021/acssuschemeng.0c06561
Liu, W., Du, H., Liu, K., Liu, H., Xie, H., Si, C., et al. (2021). Sustainable Preparation of Cellulose Nanofibrils via Choline Chloride-Citric Acid Deep Eutectic Solvent Pretreatment Combined with High-Pressure Homogenization. Carbohydr. Polym. 267, 118220. doi:10.1016/j.carbpol.2021.118220

Liu, W., Du, H., Zhang, M., Liu, K., Liu, H., Xie, H., et al. (2020b). Bacterial Cellulose-Based Composite Scaffolds for Biomedical Applications: A Review. ACS Sustainable Chem. Eng. 8, 7536-7562. doi:10.1021/ acssuschemeng.0c00125

Liu, X., Lu, M., Ai, N., Yu, F., and Ji, J. (2012). Kinetic Model Analysis of Dilute Sulfuric Acid-Catalyzed Hemicellulose Hydrolysis in Sweet Sorghum Bagasse for Xylose Production. Ind. Crops Prod. 38, 81-86. doi:10.1016/ j.indcrop.2012.01.013

Liu, X., Luan, S., and Li, W. (2019). Utilization of Waste Hemicelluloses Lye for Superabsorbent Hydrogel Synthesis. Int. J. Biol. Macromolecules 132, 954-962. doi:10.1016/j.ijbiomac.2019.04.041

Lloyd, T., and Wyman, C. E. (2003). Application of a Depolymerization Model for Predicting Thermochemical Hydrolysis of Hemicellulose. Abab 105, 53-68. doi:10.1385/ABAB:105:1-3:53

Lu, J., Zhu, W., Dai, L., Si, C., and Ni, Y. (2019). Fabrication of Thermo- and pHSensitive Cellulose Nanofibrils-Reinforced Hydrogel with Biomass Nanoparticles. Carbohydr. Polym. 215, 289-295. doi:10.1016/ j.carbpol.2019.03.100

Lu, X., Zhang, Y., Liang, Y., Yang, J., Zhang, S., and Suzuki, E. (2008a). Kinetic Studies of Hemicellulose Hydrolysis of Corn stover at Atmospheric Pressure. Korean J. Chem. Eng. 25 (2), 302-307. doi:10.1007/s11814-008-0053-y

Lu, Y., and Mosier, N. S. (2008b). Kinetic Modeling Analysis of Maleic AcidCatalyzed Hemicellulose Hydrolysis in Corn stover. Biotechnol. Bioeng. 101 (6), 1170-1181. doi:10.1002/bit.22008

Ma, C., Ma, M. G., Si, C., Ji, X. X., and Wan, P. (2021). Flexible MXene-Based Composites for Wearable Devices. Adv. Funct. Mater. 31, 2009524. doi:10.1002/ adfm.202009524

Ma, C., Yuan, Q., Du, H., Ma, M.-G., Si, C., and Wan, P. (2020). Multiresponsive MXene (Ti3C2Tx)-Decorated Textiles for Wearable Thermal Management and Human Motion Monitoring. ACS Appl. Mater. Inter. 12, 34226-34234. doi:10.1021/acsami.0c10750

Mishra, R. K., and Mohanty, K. (2018). Pyrolysis Kinetics and thermal Behavior of Waste Sawdust Biomass Using Thermogravimetric Analysis. Bioresour. Technology 251, 63-74. doi:10.1016/j.biortech.2017.12.029

Morinelly, J. E., Jensen, J. R., Browne, M., Co, T. B., and Shonnard, D. R. (2009). Kinetic Characterization of Xylose Monomer and Oligomer Concentrations during Dilute Acid Pretreatment of Lignocellulosic Biomass from Forests and Switchgrass. Ind. Eng. Chem. Res. 48, 9877-9884. doi:10.1021/ie900793p

Nabarlatz, D., Farriol, X., and Montané, D. (2004). Kinetic Modeling of the Autohydrolysis of Lignocellulosic Biomass for the Production of Hemicellulose-Derived Oligosaccharides. Ind. Eng. Chem. Res. 43, 4124-4131. doi:10.1021/ie034238i

Negahdar, L., Delidovich, I., and Palkovits, R. (2016). Aqueous-phase Hydrolysis of Cellulose and Hemicelluloses over Molecular Acidic Catalysts: Insights into the Kinetics and Reaction Mechanism. Appl. Catal. B: Environ. 184, 285-298. doi:10.1016/j.apcatb.2015.11.039

Negahdar, L., Oltmanns, J. U., Palkovits, S., and Palkovits, R. (2014). Kinetic Investigation of the Catalytic Conversion of Cellobiose to Sorbitol. Appl. Catal. B: Environ. 147, 677-683. doi:10.1016/j.apcatb.2013.09.046

Ormsby, R., Kastner, J. R., and Miller, J. (2012). Hemicellulose Hydrolysis Using Solid Acid Catalysts Generated from Biochar. Catal. Today 190 (1), 89-97. doi:10.1016/j.cattod.2012.02.050

Ostadjoo, S., Hammerer, F., Dietrich, K., Dumont, M. J., Friščić, T., and Auclair, K. (2019). Efficient Enzymatic Hydrolysis of Biomass Hemicellulose in the Absence of Bulk Water. Molecules 24 (23), 4206. doi:10.3390/molecules24234206

Patwardhan, P. R., Brown, R. C., and Shanks, B. H. (2011). Product Distribution from the Fast Pyrolysis of Hemicellulose. ChemSusChem 4 (5), 636-643. doi:10.1002/cssc.201000425

Pronyk, C., and Mazza, G. (2010). Kinetic Modeling of Hemicellulose Hydrolysis from Triticale Straw in a Pressurized Low Polarity Water Flow-Through Reactor. Ind. Eng. Chem. Res. 49, 6367-6375. doi:10.1021/ie1003625

Qi, C., Hou, S., Lu, J., Xue, W., and Sun, K. (2020). Thermal Characteristics of Birch and its Cellulose and Hemicelluloses Isolated by Alkaline Solution. Holzforschung 74 (12), 1099-1112. doi:10.1515/hf-2019-0285 
Rafiqul, I. S. M., and Mimi Sakinah, A. M. (2012). Kinetic Studies on Acid Hydrolysis of Meranti wood Sawdust for Xylose Production. Chem. Eng. Sci. 71, 431-437. doi:10.1016/j.ces.2011.11.007

Ranzi, E., Cuoci, A., Faravelli, T., Frassoldati, A., Migliavacca, G., Pierucci, S., et al. (2008). Chemical Kinetics of Biomass Pyrolysis. Energy Fuels 22, 4292-4300. doi:10.1021/ef800551t

Real, F. J., Benitez, F. J., Acero, J. L., Sagasti, J. J. P., and Casas, F. (2009). Kinetics of the Chemical Oxidation of the Pharmaceuticals Primidone, Ketoprofen, and Diatrizoate in Ultrapure and Natural Waters. Ind. Eng. Chem. Res. 48 (7), 3380-3388. doi:10.1021/ie801762p

Relvas, F. M., Morais, A. R. C., and Bogel-Lukasik, R. (2015a). Kinetic Modeling of Hemicellulose-Derived Biomass Hydrolysis under High Pressure CO2-H2O Mixture Technology. J. Supercrit. Fluids 99, 95-102. doi:10.1016/ j.supflu.2015.01.022

Relvas, F. M., Morais, A. R. C., and Bogel-Lukasik, R. (2015b). Selective Hydrolysis of Wheat Straw Hemicellulose Using High-Pressure $\mathrm{CO} 2$ as Catalyst. RSC Adv. 5 (90), 73935-73944. doi:10.1039/c5ra14632a

Rissanen, J. V., Grénman, H., Willför, S., Murzin, D. Y., and Salmi, T. (2014). Spruce Hemicellulose for Chemicals Using Aqueous Extraction: Kinetics, Mass Transfer, and Modeling. Ind. Eng. Chem. Res. 53 (15), 6341-6350. doi:10.1021/ ie500234t

Rissanen, J. V., Murzin, D. Y., Salmi, T., and Grénman, H. (2016). Aqueous Extraction of Hemicelluloses from spruce - from Hot to Warm. Bioresour. Technology 199, 279-282. doi:10.1016/j.biortech.2015.08.116

Rivas, S., González-Muñoz, M. J., Vila, C., Santos, V., and Parajó, J. C. (2013). Manufacture of Levulinic Acid from Pine Wood Hemicelluloses: A Kinetic Assessment. Ind. Eng. Chem. Res. 52 (11), 3951-3957. doi:10.1021/ie3018725

Rivas, S., Vila, C., Santos, V., and Parajó, J. C. (2016). Furfural Production from Birch Hemicelluloses by Two-step Processing: a Potential Technology for Biorefineries. Holzforschung 70 (10), 901-910. doi:10.1515/hf-2015-0255

Saeman, J. F. (1945). Kinetics of Wood Saccharification - Hydrolysis of Cellulose and Decomposition of Sugars in Dilute Acid at High Temperature. Ind. Eng. Chem. 37 (1), 43-52. doi:10.1021/ie50421a009

Salmi, T., Murzin, D. Y., Mäki-Arvela, P., Kusema, B., Holmbom, B., Willför, S., et al. (2014). Kinetic Modeling of Hemicellulose Hydrolysis in the Presence of Homogeneous and Heterogeneous Catalysts. Aiche J. 60 (3), 1066-1077. doi:10.1002/aic.14311

Santos, V. T. d. O., Siqueira, G., Milagres, A. M. F., and Ferraz, A. (2018). Role of Hemicellulose Removal during Dilute Acid Pretreatment on the Cellulose Accessibility and Enzymatic Hydrolysis of Compositionally Diverse Sugarcane Hybrids. Ind. Crops Prod. 111, 722-730. doi:10.1016/ j.indcrop.2017.11.053

Santucci, B. S., Maziero, P., Rabelo, S. C., Curvelo, A. A. S., and Pimenta, M. T. B. (2015). Autohydrolysis of Hemicelluloses from Sugarcane Bagasse during Hydrothermal Pretreatment: a Kinetic Assessment. Bioenerg. Res. 8 (4), 1778-1787. doi:10.1007/s12155-015-9632-z

Scheller, H. V., and Ulvskov, P. (2010). Hemicelluloses. Annu. Rev. Plant Biol. 61, 263-289. doi:10.1146/annurev-arplant-042809-112315

Sella Kapu, N., and Trajano, H. L. (2014). Review of Hemicellulose Hydrolysis in Softwoods and Bamboo. Biofuels, Bioprod. Bioref. 8 (6), 857-870. doi:10.1002/ bbb. 1517

Shatalov, A. A. (2020). Polyoxometalate-catalyzed Hydrolysis of the Hemicelluloses by (Mo-V-P)-Heteropolyacids-Statistical Modeling Using Response Surfaces. Carbohydr. Polym. 236, 116091. doi:10.1016/ j.carbpol.2020.116091

Shen, J., and Wyman, C. E. (2011). A Novel Mechanism and Kinetic Model to Explain Enhanced Xylose Yields from Dilute Sulfuric Acid Compared to Hydrothermal Pretreatment of Corn stover. Bioresour. Technology 102 (19), 9111-9120. doi:10.1016/j.biortech.2011.04.001

Shi, S., Guan, W., Kang, L., and Lee, Y. Y. (2017). Reaction Kinetic Model of Dilute Acid-Catalyzed Hemicellulose Hydrolysis of Corn Stover under High-Solid Conditions. Ind. Eng. Chem. Res. 56 (39), 10990-10997. doi:10.1021/ acs.iecr.7b01768

Soleimani, M., Tabil, L. G., and Panigrahi, S. (2018). A Kinetic Study of Xylose Recovery from a Hemicellulose-Rich Biomass for Xylitol Fermentative Production. Chem. Eng. Commun. 206 (2), 193-206. doi:10.1080/ 00986445.2018.1478294
Sun, L., Chen, J. Y., Negulescu, I. I., Moore, M. A., and Collier, B. J. (2011a). Kinetics Modeling of Dynamic Pyrolysis of Bagasse Fibers. Bioresour. Technology 102, 1951-1958. doi:10.1016/j.biortech.2010.08.109

Sun, X.-F., Gan, Z., Jing, Z., Wang, H., Wang, D., and Jin, Y. (2015b). Adsorption of Methylene Blue on Hemicellulose-Based Stimuli-Responsive Porous Hydrogel. J. Appl. Polym. Sci. 132 (10), a-n. doi:10.1002/app.41606

Sun, X.-F., Liu, B., Jing, Z., and Wang, H. (2015a). Preparation and Adsorption Property of Xylan/poly(acrylic Acid) Magnetic Nanocomposite Hydrogel Adsorbent. Carbohydr. Polym. 118, 16-23. doi:10.1016/j.carbpol.2014.11.013

Sun, X.-F., Wang, H.-h., Jing, Z.-X., and Mohanathas, R. (2013). Hemicellulosebased pH-Sensitive and Biodegradable Hydrogel for Controlled Drug Delivery. Carbohydr. Polym. 92 (2), 1357-1366. doi:10.1016/j.carbpol.2012.10.032

Sun, Y., Lu, X., Zhang, S., Zhang, R., and Wang, X. (2011b). Kinetic Study for $\mathrm{Fe}(\mathrm{NO} 3) 3$ Catalyzed Hemicellulose Hydrolysis of Different Corn stover Silages. Bioresour. Technology 102 (3), 2936-2942. doi:10.1016/j.biortech.2010.11.076

Tizazu, B. Z., and Moholkar, V. S. (2018). Kinetic and Thermodynamic Analysis of Dilute Acid Hydrolysis of Sugarcane Bagasse. Bioresour. Technology 250, 197-203. doi:10.1016/j.biortech.2017.11.032

Wan, L., Gao, Z., Wu, B., Cao, F., Jiang, M., Wei, P., et al. (2021). Hydrolysis of Corncob Hemicellulose by Solid Acid Sulfated Zirconia and its Evaluation in Xylitol Production. Appl. Biochem. Biotechnol. 193 (1), 205-217. doi:10.1007/ s12010-020-03412-9

Wang, H., Du, H., Liu, K., Liu, H., Xu, T., Zhang, S., et al. (2021). Sustainable Preparation of Bifunctional Cellulose Nanocrystals via Mixed H2SO4/formic Acid Hydrolysis. Carbohydr. Polym. 266, 118107. doi:10.1016/ j.carbpol.2021.118107

Wang, H., Xie, H., Du, H., Wang, X., Liu, W., Duan, Y., et al. (2020a). Highly Efficient Preparation of Functional and Thermostable Cellulose Nanocrystals via H2SO4 Intensified Acetic Acid Hydrolysis. Carbohydr. Polym. 239, 116233. doi:10.1016/j.carbpol.2020.116233

Wang, R., Yue, J., Jiang, J., Li, J., Zhao, J., Xia, H., et al. (2020b). Hydrothermal CO2-assisted Pretreatment of Wheat Straw for Hemicellulose Degradation Followed with Enzymatic Hydrolysis for Glucose Production. Waste Biomass Valor. 12 (3), 1483-1492. doi:10.1007/s12649-020-01103-4

Wang, X., Hu, M., Hu, W., Chen, Z., Liu, S., Hu, Z., et al. (2016). Thermogravimetric Kinetic Study of Agricultural Residue Biomass Pyrolysis Based on Combined Kinetics. Bioresour. Technology 219, 510-520. doi:10.1016/ j.biortech.2016.07.136

Wang, Y., Cao, X., Zhang, R., Xiao, L., Yuan, T., Shi, Q., et al. (2018). Evaluation of Xylooligosaccharide Production from Residual Hemicelluloses of Dissolving Pulp by Acid and Enzymatic Hydrolysis. RSC Adv. 8 (61), 35211-35217. doi:10.1039/c8ra07140c

White, J. E., Catallo, W. J., and Legendre, B. L. (2011). Biomass Pyrolysis Kinetics: A Comparative Critical Review with Relevant Agricultural Residue Case Studies. J. Anal. Appl. Pyrolysis 91 (1), 1-33. doi:10.1016/j.jaap.2011.01.004

Xu, C., Pranovich, A., Vähäsalo, L., Hemming, J., Holmbom, B., Schols, H. A., et al. (2008). Kinetics of Acid Hydrolysis of Water-Soluble Spruce O-Acetyl Galactoglucomannans. J. Agric. Food Chem. 56, 2429-2435. doi:10.1021/ if703702y

Xu, J., Li, C., Dai, L., Xu, C., Zhong, Y., Yu, F., et al. (2020a). Biomass Fractionation and Lignin Fractionation towards Lignin Valorization. ChemSusChem 13, 4284-4295. doi:10.1002/cssc.202001491

Xu, R., Du, H., Liu, C., Liu, H., Wu, M., Zhang, X., et al. (2021a). An Efficient and Magnetic Adsorbent Prepared in a Dry Process with Enzymatic Hydrolysis Residues for Wastewater Treatment. J. Clean. Prod. 313, 127834. doi:10.1016/ j.jclepro.2021.127834

Xu, R., Liu, K., Du, H., Liu, H., Cao, X., Zhao, X., et al. (2020b). Falling Leaves Return to Their Roots: A Review on the Preparation of $\gamma$-Valerolactone from Lignocellulose and its Application in the Conversion of Lignocellulose. ChemSusChem 13, 6461-6476. doi:10.1002/cssc.202002008

Xu, T., Du, H., Liu, H., Liu, W., Zhang, X., Si, C., et al. (2021b). Advanced Nanocellulose-Based Composites for Flexible Functional Energy Storage Devices. Adv. Mater. 2021, 2101368. doi:10.1002/adma.202101368

Xu, Y., Wang, P., Xue, S., Kong, F., Ren, H., and Zhai, H. (2020c). Green Biorefinery - the Ultra-high Hydrolysis Rate and Behavior of Populus Tomentosa Hemicellulose Autohydrolysis under Moderate Subcritical Water Conditions. RSC Adv. 10 (32), 18908-18917. doi:10.1039/D0RA02350G 
Yáñez, R., Romaní, A., Garrote, G., Alonso, J. L., and Parajó, J. C. (2009). Processing of Acacia Dealbata in Aqueous Media: First Step of a Wood Biorefinery. Ind. Eng. Chem. Res. 48, 6618-6626. doi:10.1021/ie900233x

Yang, G. C. C., and Lee, H.-L. (2005). Chemical Reduction of Nitrate by Nanosized Iron: Kinetics and Pathways. Water Res. 39 (5), 884-894. doi:10.1016/ j.watres.2004.11.030

Yang, H., Yan, R., Chen, H., Lee, D. H., and Zheng, C. (2007). Characteristics of Hemicellulose, Cellulose and Lignin Pyrolysis. Fuel 86 (12-13), 1781-1788. doi:10.1016/j.fuel.2006.12.013

Yang, X., Xie, H., Du, H., Zhang, X., Zou, Z., Zou, Y., et al. (2019). Facile Extraction of Thermally Stable and Dispersible Cellulose Nanocrystals with High Yield via a green and Recyclable FeCl3-Catalyzed Deep Eutectic Solvent System. ACS Sustainable Chem. Eng. 7, 7200-7208. doi:10.1021/acssuschemeng.9b00209

Yedro, F. M., Grénman, H., Rissanen, J. V., Salmi, T., García-Serna, J., and Cocero, M. J. (2017). Chemical Composition and Extraction Kinetics of Holm Oak (Quercus ilex) Hemicelluloses Using Subcritical Water. J. Supercrit. Fluids 129, 56-62. doi:10.1016/j.supflu.2017.01.016

Yeo, J. Y., Chin, B. L. F., Tan, J. K., and Loh, Y. S. (2019). Comparative Studies on the Pyrolysis of Cellulose, Hemicellulose, and Lignin Based on Combined Kinetics. J. Energ. Inst. 92 (1), 27-37. doi:10.1016/j.joei.2017.12.003

Zaera, F. (2002). Kinetics of Chemical Reactions on Solid Surfaces: Deviations from Conventional Theory. Acc. Chem. Res. 35, 129-136. doi:10.1021/ar000193v

Zazo, J. A., Casas, J. A., Mohedano, A. F., Gilarranz, M. A., and Rodríguez, J. J. (2005). Chemical Pathway and Kinetics of Phenol Oxidation by Fenton's Reagent. Environ. Sci. Technol. 39, 9295-9302. doi:10.1021/es050452h

Zhang, J., Chen, T., Wu, J., and Wu, J. (2014). A Novel Gaussian-DAEM-Reaction Model for the Pyrolysis of Cellulose, Hemicellulose and Lignin. RSC Adv. 4, 17513. doi:10.1039/c4ra01445f

Zhang, M., Du, H., Liu, K., Nie, S., Xu, T., Zhang, X., et al. (2021). Fabrication and Applications of Cellulose-Based Nanogenerators. Adv. Compos. Hybrid. Mater. 4. doi:10.1007/s42114-021-00312-2

Zheng, Y., Yu, Y., Lin, W., Jin, Y., Yong, Q., and Huang, C. (2021). Enhancing the Enzymatic Digestibility of Bamboo Residues by Biphasic Phenoxyethanol-Acid
Pretreatment. Bioresour. Technology 325, 124691. doi:10.1016/ j.biortech.2021.124691

Zhong, C., Wang, C., Huang, F., Wang, F., Jia, H., Zhou, H., et al. (2015). Selective Hydrolysis of Hemicellulose from Wheat Straw by a Nanoscale Solid Acid Catalyst. Carbohydr. Polym. 131, 384-391. doi:10.1016/j.carbpol.2015.05.070

Zhou, H., Long, Y., Meng, A., Chen, S., Li, Q., and Zhang, Y. (2015). A Novel Method for Kinetics Analysis of Pyrolysis of Hemicellulose, Cellulose, and Lignin in TGA and Macro-TGA. RSC Adv. 5 (34), 26509-26516. doi:10.1039/ C5RA02715B

Zhu, L., and Zhong, Z. (2020). Effects of Cellulose, Hemicellulose and Lignin on Biomass Pyrolysis Kinetics. Korean J. Chem. Eng. 37 (10), 1660-1668. doi:10.1007/s11814-020-0553-y

Conflict of Interest: The authors declare that the research was conducted in the absence of any commercial or financial relationships that could be construed as a potential conflict of interest.

The reviewer (JX) declared a past co-authorship with one of the authors (MM) to the handling Editor.

Publisher's Note: All claims expressed in this article are solely those of the authors and do not necessarily represent those of their affiliated organizations, or those of the publisher, the editors, and the reviewers. Any product that may be evaluated in this article, or claim that may be made by its manufacturer, is not guaranteed or endorsed by the publisher.

Copyright (C) 2021 Yuan, Liu, Ma, Ji, Choi and Si. This is an open-access article distributed under the terms of the Creative Commons Attribution License (CC BY). The use, distribution or reproduction in other forums is permitted, provided the original author(s) and the copyright owner(s) are credited and that the original publication in this journal is cited, in accordance with accepted academic practice. No use, distribution or reproduction is permitted which does not comply with these terms. 